\title{
Experiences of the Mobile Injection Team for Multidrug Resistant-Tuberculosis Patients in Ugu District, Kwazulu-Natal
}

\author{
Sitha Devi Arjun*, DLitt et Phil and Bethabile L Dolamo DCur \\ Department of Health Studies, University of South Africa, South Africa \\ Received: 制: August 14, 2018; Published: 制 September 14, 2018 \\ *Corresponding author: Sitha Devi Arjun, Department of Health Studies, University of South Africa, South Africa
}

\begin{abstract}
The purpose of this paper is to describe the experiences of the mobile injection team (MTI) for multidrug resistant- tuberculosis with an aim of identifying the challenges facing the team and the institution providing the service. Giorgi's essential phenomenological research method was conducted. Convenience census sampling was used as all the seven members of the MIT were included. The inclusion criteria were that at least six months' working experience with MDR-TB patients in a MIT at Ugu District. And be an enrolled nurse registered with SANC, and/or be a TB assistant, be willing to participate in the study and be located at the decentralised or satellite site. Data were collected through individual in-depth interviews with the participants during November to December 2014 at both the decentralised and satellite hospitals and were analysed using Giorgi's method of data analysis. The research findings revealed four broad themes (the perceptions held by the team, challenges, available support and needs to promote the service) and 73 sub-themes. The findings of the study indicated that the MIT experiences many challenges in the community and need to be supported in order to provide quality care to the patients.
\end{abstract}

\section{Introduction and Background Information}

Tuberculosis (TB) is curable, as demonstrated by numerous controlled trials that have shown that a six-month regimen of rifampicin and isoniazid, supplemented by pyrazinamide and streptomycin or ethambutol for the first two months, will provide a cure in more than $95 \%$ of cases if the medication is taken correctly [1]. If medication is not taken correctly, drug-resistant TB (DRTB) can develop. Multidrug resistant-tuberculosis (MDR-TB) is defined by the World Health Organization (WHO) as TB caused by Mycobacterium tuberculosis resistant in vitro to the effects of isoniazid and rifampicin [2]. MDR-TB is a laboratory diagnosis; it can be diagnosed by means of a GeneXpert (GXP), TB culture and susceptibility testing [3] GeneXpert is a relatively new diagnostic tool for TB diagnosis in South Africa. This test has an advantage over the existing TB smear microscopy because it has higher sensitivity, specificity and identifies many patients that would not have been diagnosed using TB microscopy.

In 2007, a total of 2799 cases (28 cases per 100000 population) of MDR-TB were identified in KwaZulu-Natal. TB prevalence was 1,200 cases per 100000 population, and MDR accounted for $2.3 \%$ of reported cases in the province. XDR-TB cases accounted for $9.6 \%$ of MDR TB cases [4]. In 2007, MDR TB in the districts ranged from 10 (uThukela) to 57 (Umkhanyakude) cases per 100 000population. Incidence of MDR-TB was highest for Umkhanyakude and
Umzinyathi districts. The proportion of MDR-TB cases that were XDR-TB cases also varied among districts (1.2\%-53.1\%). The two districts with the highest level of MDR-TB (Umkhanyakude and Umzinyathi) had the highest and the lowest XDR-TB prevalence, respectively.

Of the 1549 patients prospectively enrolled in the study conducted by Loveday [5], 736 were treated at the communitybased sites and 813 at the centralised hospital. At the communitybased sites significantly more patients were cured $(50.7 \%$ vs. $34.4 \%)$, and significantly fewer patients defaulted $(14.5 \%$ vs. $28.3 \%$ ). In addition, more patients achieved a successful treatment outcome (58\%) than at the centralised hospital (54\%). Their study concluded that community-based care is more effective than care in a centralised setting, based on similar treatment success rate, lower defaulter rate and shorter time to treatment initiation. Even in the presence of HIV co-infection, community-based care increased treatment success.

In a study by Meressa [6], 79 outpatients were initiated on MDR-TB therapy at home using roving nurses to provide injections and to supervise directly observes treatment (DOT). Though this group had lower rates of death or treatment failure compared with patients who began treatment as inpatients, these outcomes were influenced by a more favourable baseline clinical status at the onset 
of treatment, leading to their selection as outpatient candidates for Ethiopia's pilot outpatient programme. They argued that given the individual and public health impact of high loss to follow-up rates, community-based interventions should be considered an essential component of MDR-TB treatment programmes.

Ugu District of KwaZulu-Natal (KZN) employed for the first time in December 2011 four mobile injection teams (MITs). At a meeting held in October 2011, the Ugu District Health (Office resolved to employ 22 teams for the district. Each team consisted of one enrolled nurse (EN) and one TB assistant (TBA) as per the WHO MDR-TB guidelines. The Ugu District Health Office placed two teams at the Ugu District decentralised MDR-TB site and two teams at the satellite site, which is a specialised TB hospital. The researcher has been employed at the satellite site as Assistant Manager Nursing since May 2011. The research study was conducted at both the decentralised and the satellite sites in the respective hospitals.

As per the Management of DR-TB policy guideline, these teams administer injections to patients at their homes, supervise the intake of oral tablets, and also educate patients' families about infection control. Patients who are unable to access a health facility daily should, for the duration of the injectable phase of their treatment, be visited five times a week at home by an MIT which should consist of a driver (TB Assistance) and an enrolled nurse. The functions of the mobile team are to provide directly observed treatment short course (DOTS) to all DR-TB patients in the area; to educate patients, their families and their community on TB; to monitor treatment side effects; to refer patients to the nearest health facility when necessary; and to maintain appropriate records [7].

\section{Statement of the Research Problem}

Since the initiation of the MIT programme in 2011, when an MDR-TB patient is discharged, the injection team takes the patient home and thereafter visits the patient's home daily to administer injections. The teams which are based at the hospital have to travel long distances to reach outpatients. Most of the patients live in rural areas that are inaccessible by vehicles, and at times the teams therefore have to walk to get to patients' homes. The Ugu District Health Office does not provide cellular phones to contact patients telephonically, yet very often the patients are not at home when the team arrives. Ugu district was the first district in KZN to introduce mobile injection team for treatment of MDR-TB patients at home. No research describing the experiences of the MITs has previously been conducted at these hospitals. Therefore, the researcher found it important to investigate the mobile injection team's experiences of caring for multidrug resistant-tuberculosis outpatients in Ugu district KwaZulu-Natal.

\section{Purpose of the Study}

The purpose of this phenomenological research study was to promote the functioning of the MDR-TB mobile injection team by designing and recommending an MIT guideline based on the experiences of the team members. The objectives formulated to guide the study were to describe the experiences of the MIT, gain an understanding of their experience, develop a guideline for the MIT and indicate what support does the MIT require to provide quality nursing care to the patients.

The following research questions were formulated in order to achieve the purpose of the study: -

a) What are the lived experiences of the MDR-TB mobile injection teams in Ugu District?

b) What guidelines should be recommended to improve the activities of the MIT

c) What support do the MIT require?

\section{Definitions of Key Concepts}

Enrolled Nurse (EN): An EN is registered with South African Nursing Council as a person who is educated to practise basic nursing care in the manner and to the level as prescribed [8]. The scope of practice of an enrolled nurse is to implement a nursing regimen planned and initiated by a registered nurse or registered midwife and carried out under his direct or indirect supervision [9]. Distinguishing devices are the epaulettes and badges worn by nurses and midwives that indicate the capacity or capacities in which the wearer is registered or enrolled. White epaulette and maroon badge is worn by an EN as prescribed by SANC. For this study, an EN is the nurse in the MIT who administers injections to the patients, observes side effects, and provides advice where necessary.

Experiences: The term "experiences" refers to the emotional sensations one undergoes [10]. To learn through experience involves practice, involvement, participation, familiarity or observation. To gain experience involves developing skills, knowledge, background, understanding and know-how [11]. For the purposes of this study, "experiences" will refer to the Ugu District MITs' practices, involvement, participation, familiarity or observations in the care of MDR-TB outpatients.

Multidrug Resistant-Tuberculosis: MDR-TB is defined as TB caused by Mycobacterium tuberculosis resistant in vitro to the effects of isoniazid and rifampicin [2], the two most potent TB drugs. These drugs are used to treat all persons with TB disease.

TB Assistant: The TB Assistant is the assistant who accompanies the EN and provides health education to the patients' relatives and the community [7]. In this study the TB Assistant is also the driver.

\section{Research Methodology}

This study employed a qualitative methodology based on Giorgi's existential phenomenological research method. Phenomenology focuses on the meaning of the lived experiences of humans [12]. Giorgi's existential phenomenological research approach follows the five steps: assuming phenomenology attitude; read of interview to attain sense of the whole; determination of primary meaning unites; transforming of meaning unites to psychological statements; and synthesize of psychological general and essential structure of experiences based on constituents (Hasanvand sa) and was therefore appropriate for this study. The phenomenological approach was employed for this research because the researcher was seeking to learn about the lived experiences of the MDR-TB 
MITs in Ugu District. Giorgi's method of data analysis was used. King's model on individuals whose interactions in groups within the social systems influence behaviour within the systems. As humans interact with their environment, their perceptions influence their behaviour and their health [13]. This model was used in this study to analyse the perceptions, judgements and actions of the patients, ENs and TB Assistants in their everyday interactions. The nurse and the patient as individuals form a group and interact to facilitate achievement of health-related goals resolve problems by communicating and setting future goals.

\section{Ethical Issues}

The Research and Ethics Committee of the Department of Health Studies, University of South Africa (UNISA), reviewed and approved the research proposal. Permission to conduct the study under KwaZulu-Natal province department of health was requested and permission granted. Letters were then written to the hospital managers from both hospitals to request permission to conduct the study, and permission was given. Thereafter permission was obtained from the operational managers to conduct in-depth individual interviews with the ENs and the TB Assistants. Informed consent to participate in the study was signed by each participant following a thorough explanation of the purpose of the study and presentation of the ethical clearance certificate; together with the letters of approval from the relevant authorities. Confidentiality was maintained by replacing the names of the participants with their designations, and the hospital's names with "Hospital A" and "Hospital B" (with a neighbouring hospital referred to as "Hospital C").

\section{Data Collection}

Convenience census sampling was used as all the seven members of the MIT were included. The inclusion criteria were that at least six months' working experience with MDR-TB patients in a MIT at Ugu District. And be an enrolled nurse registered with SANC, or be a TB assistant, be willing to participate in the study and be located at the decentralised or satellite site. Agreement was reached with participants on times and place to meet for interviews. Arrangement was made to acquire a quiet venue within the hospital. The participants were interviewed by the researcher at mutually acceptable dates and times in a private office away from the main MDR-TB wards, and each interview lasted approximately one hour. This was a convenient time set by the participants so as not to disrupt the routine of the outreach injection mobile team. Permission to audio record the interview was granted by participants. All members of the outreach injection team were interviewed using unstructured interviews. This study described the lived experiences of three ENs and four TBAs in the MDR-TB outreach injection team who had worked at two MDR-TB hospitals over two years. Data collection started in November to December 2014 at different dates when the participants were available. The tape-recorded interviews were kept under lock and key in the researcher's office.

\section{Data Analysis and Discussion of the Results}

Interviews were tape-recorded and transcribed by the researcher verbatim. Interviews were terminated when all seven participants had been interviewed and data saturation had been reached. Saturation of data occurs when additional sampling provides no new information, that is, when no new themes or essences have emerged from the participants and the data are repeated. It usually involves a small sample [14]. Giorgi's method for data analysis was used. According to Brown (sa) the data analysis in Giorgi's method for data analysis is done once the interview has been transcribed and the text has become the empirical evidence to be analysed for its psychological implications. According to Hasanvand (sa) the researcher is to take a fresh look at the data (brackets), this is the first step called phenomenological attitude. The second step in Giorgi's data analysis is read of interview to attain sense of the whole. The third step is determination of primary meaning unites, and step four is transforming of meaning unites to psychological statements. The fifth and last step is synthesize of psychological general or essential structure of experience based on constituents. The researcher only gives an interpretation after seeing and following the description of the experience, just as it appears in the consciousness of the participant which leads it to catch its meaning [15]. The themes that emerged from this study were as follows; perceptions held by the team, challenges, available support and needs in promoting this service.

\section{Perceptions Held by the Team}

When the programme initially commenced, no one knew how it was going to survive as this was the first time Ugu District had initiated MDR-TB outreach mobile injection teams. The teams learnt that teamwork was very important. Perception is the comprehensive concept in personal systems. According to Leddy [13], perception is a characteristic of a human process of interaction and along with communication provides a channel for passage of information from one person to another.

"Eh ... I'm experiencing working in a team. Firstly, I'm experiencing ehhh ... ehhh teamwork and I'm experiencing ehh ... education skills like educating people education, educating people about different topics concerning health ehh working with ehh people, sick people ehh ahh and especially teamwork with the team that we are working with." [TBA 1]

When patients were discharged from inpatient care to the injection team, obtaining the correct physical address of the patient was important as the team would be visiting the patient daily. Patients receiving outpatient care responded well to treatment and showed appreciation of the programme as they did not have to stand for long periods of time in queues at the clinic waiting for treatment. In King's model, health assumes achievement of maximum potential for daily living and an ability to function in social roles [13].

"Patients are happy that they are getting treatment at home." [TBA 3]

"We have to involve them, the whole family even then, even if he got he also gonna need support of family support so we might, so we need to educate the family as well." [EN 4]

The teams attend to patients who live in deep rural areas, and the team members realised that the poor are susceptible to contracting and spreading TB. 
"... most of them they are from the poor families ... some of them they are living in a one room maybe four or five of them." [TBA 2]

They found that providing health education and counselling to the patients and their families was key to preventing the spread of TB and the development of further resistance. Family involvement was found to be important for the patients to ensure treatment adherence and compliance. Family becomes involved during admission of the patient. Should the patient not want to disclose their TB status to their family, the patient would receive ongoing counselling from the ward staff and be referred to the Social Worker for further counselling and family intervention.

"We give them health education, ahh we inject them, we teach them how to plant, how to plant vegetables, we teach them how to take the treatment correctly and what we are I've learnt about the patient that ahh they are responding well everything that we told them they do." [EN 3]

When the patient discloses their TB status to their family, the Social Worker also does a home visit to get the family involved in the treatment plan for the patient to ensure treatment adherence of the patient.

\section{Challenges}

The teams experienced many challenges as this was the first time that Ugu Health District had introduced and implemented the MDR-TB mobile injection teams. The participants indicated that they felt there was a lack of appreciation and support from management for their work and their working conditions, particularly during the pregnancy of a team member. The working conditions did not change but travelling long distances while pregnant on gravel bumpy roads impacted on her health as verbalised by her.

When they were first employed, because it was a new programme, there were no job descriptions and performance agreements in place that detailed the job that they were expected to do. In addition, the participants voiced concern over not having an operational manager to oversee the teams, which has resulted in a lack of leadership and direction. No specific in-service education is regularly provided for the teams, but only general information that they receive at the compulsory in-service training in the wards in the mornings.

There were multiple challenges in relation to travel and transport. The patients' homes are scattered in deep rural areas, and are quite a distance from the hospitals, so travelling to patients' homes was very time consuming.

"Mostly on gravel road (laugh) 90-95\% of our roads are gravel roads. I think only $5 \%$ still on the national road, the N2. Once you branch to the patient, it is gravel road. Some you cannot call them gravel road you just travel on the grass." "And the vehicles that we are using, they to put it, they are just useless bakkies. Yes because you can only drive them if the weather is okay. If it's raining even if it is drizzling they don't move on grass. We've been stuck for I don't know for about ten times been stuck on the mud." [EN 1]

"On daily basis I am driving plus or minus 450 kilometres because our patients are all over ... we used to start from Port Edward to
Harding and close to Sisonke municipality the whole area, you understand ... Yes, when you go to KwaNyuswa, Lake Eland also I go to Qobeni, KwaMache and go straight to Gcilima when you go to Port Edward so they are scattered all over." [TBA 3]

“... sometimes you have to park that vehicle and walk plus or minus 10 kilometres to reach the patient because even the car won't be able to go to the premises whether it's raining or not raining." [TBA 3]

Direct contact with the patients often lasted for only a few minutes, and when more patients were allocated to a team, patient contact decreased even further. Oral treatment could not be monitored with all the patients, as at times patients had taken their medication by the time the team had arrived; however, pill counts were performed to establish if patients had taken their treatment. In a study by Brust et al. [15], it revealed that the rural landscape, poor roads and large distances between family compounds, injections teams arrive at patients' homes at different times each day-often after the patients' morning dose of oral medications.

The type of vehicle allocated to the mobile teams (a bakkie) was not suitable for the dirt and gravel roads that they had to travel on daily. On rainy days the poorly constructed rural roads become impassable, and the vehicles could not reach the patients' homes, so the patients miss their injections for that day. When the roads become impassable, the patient is informed to go to their nearest clinic to receive the injections. At times the vehicles get stuck in the mud and the community is requested to assist, sometimes demanding payment for such assistance. The team members also complained about having to wash their vehicles after a long day on the road, as there was no company employed to do so [16].

Trip sheets posed a challenge as they are usually filled in the day before a trip, but often on the morning of a trip the teams would find that their allocation of vehicles had been changed by the transport department, and this caused a delay in the teams' schedule of visits. This showed lack of planning by the transport officials.

Patients had to be transported upon discharge from the wards to their homes, so that the mobile injection teams could see exactly where they lived, but the bakkies used by the teams were not suitable for the transportation of patients, as the patients had to sit in the open back area. A car could be allocated when a patient needs to be taken home and the patient could sit in the back of the car wearing a mask. In addition, the departmental policy does not allow patients to be transported using a government vehicle. Even so, teams were required to transport patients to their homes. If their patients' condition changed, and the doctor to whom it was reported requested that the patient be brought back, then the teams would have to transport the patient back to the hospital $[17,18]$.

Another situation that required the teams to break the rules was when they had to walk long distances to patients' homes in areas where their vehicle could not drive. Vehicle theft and safety was an issue. At times one team member stayed with the vehicle while the other went to see the patient. Government vehicles should always be monitored by their drivers, but for the sake of their personal safety, both team members would walk together and 
leave the vehicle behind. Personal safety was a big challenge for the participants. The team members were afraid of walking alone in these rural areas and had to go together to support one another. Walking in these areas was a challenge as the team members had to wear sturdy shoes to walk the distances, and often wet-weather gear, but they emphasised that they did not receive a uniform allowance or danger allowance. When visiting patients the team members wore $\mathrm{N} 95$ masks to prevent them from contracting MDRTB, but their fear of contracting MDR-TB remained [19].

Some patients do not show appreciation as on the way to and from the patients' homes, the team sometimes came across dogs which the patients let loose to prevent the MIT from giving them injections. A TBA was bitten by a dog and had to receive medical treatment. This was treated as an injury on duty.

"Sometimes the patients they, if they don't want, if they don't want injections anymore they just leave dogs for you so that you can't get in and they can't get injections." [EN 2]

"That patient didn't give me ... gave me a hard time cos each and every time we go there maybe he is going to have a knife you see,"The sangoma was not that violent but then she had a sjambok she actually tried to hit me with the sjambok just then I closed the window." [EN 4]

The teams also feared gangsters in the communities and the violent patients that they sometimes had who wanted to fight with them. Although the teams had to inject the patients daily, even on public holidays, some patients still refused to take their injections. At times, they were told that the patient is in the tavern and would find the patient drunk. Sometimes patients' lack of adherence to the treatment would lead to their re-hospitalisation.

Other challenges for the teams had to do with resources and supplies. There were essential resources that were not available, like stethoscopes to monitor patients' vital signs and supplies like bandages or even a first-aid kit. The teams provided injection services only and no other services. When the patients or community members requested assistance for minor ailments, the team could not assist, and they would refer the community members or the patients to their local clinics for further management. Kanamycin ampoules were also a challenge to administer, as they are poorly manufactured and would often break into pieces when being opened. Any kanamycin that spills turns to superglue when in contact with the skin, but unfortunately nothing could be done to change the ampoules supplied to the Department of Health. A product complaint form had to be completed and submitted to the Provincial Medical Supply Service, addressed to the Chief Pharmacist for investigation and reporting to the manufacturer.

Communication initially posed a great challenge, because no cell phones were provided for the teams. Later on, however, cell phones were donated to the teams with R50 airtime, but signal and network challenges remained an issue. The patients' home and family environments played a crucial role in their adherence to medication and their recovery. Where family support is received, the patient is more likely to adhere to the treatment programme, so the team members spent a great deal of time educating the families and encouraging such support. If the patient has not disclosed their TB status to their family, the patient would receive ongoing counselling from the time of admission and be referred to the Social Worker for further counselling [20].

\section{Support}

The teams received support from their colleagues in the MDR-TB wards. They attend the wards' daily in-service training programme, and when the team requires supplies such as bandages, then the ward staff assist. At Hospital B the team was pleased to report that there was a private company that management had tasked with washing the vehicles. The management team had meetings with them monthly and with the district health team quarterly where they could air their challenges and receive recommendations. The meetings were held in the mornings so that after the meetings the teams could go to attend to their patients. The team indicated that when they had supervisors, the supervisors had been very helpful and had assisted them with their queries [21].

"We have our meetings and then we find our flaws and our supervisor and the management always advise us, okay, this is what we do, this is how we can improve on our services, cos we do have flaws that still to be polished so we always have that support. Yes, we do have policies but the 2014 TB guidelines are like I still like to get my, read the TB guidelines the 2014 one." [EN 4]

\section{Needs to Promote the Service}

The teams requested further training to ensure more effective service delivery. They also requested that a team: patient ratio be established, as when there are many patients allocated to one team, then patient contact time is minimal. $4 \times 4$ vehicles are required for the gravel roads, especially when it rains, as roads become impassable and ordinary vehicles get stuck. Additional teams are required because the number of MDR-TB patients is increasing, as diagnosis by GeneXpert is faster [22].

"It depends now we've got seven patients. Previously we used to have 15 patients and above but it depends because some of them, they on continuation phase, you understand. Like if discharged from the ward it goes to outreach team, yes some of them they continue with on continuation phase, it depends, today there may be seven, tomorrow there may be ten, yah," [TBA 3]

Health education for patients, relatives, community members and nurses must be strengthened to prevent the spread of TB and to ensure treatment adherence by patients with MDR-TB. Patients need to be supported during care as the treatment programme is lengthy and requires sustained motivation and commitment from patients. The needs described by the outreach team, if and when attended to, will improve service delivery to the patients in the community [23-25].

Guidelines were formulated in this study using themes based on the participants' experiences which included teaching, policy, guidelines, patient care, patient referrals, essential drugs, emergency contacts, equipment and supplies, travel routes, transport, orientation of the MIT, structure of the team, allowances and staff support. 


\section{Conclusion}

It is important to understand the experiences of the MIT as it appears that the outreach MIT experiences many challenges in the community and with the patients allocated to the team. Their experiences with patients are generally positive, yet the challenges that they experience in providing their services outweigh these positive experiences with the patients. Therefore, the team needs to be supported because although they receive support from management at times, it is insufficient. They do, however, at times receive support from their colleagues and from the wards. Hence guidelines have been formulated to improve the functioning of the MIT.

\section{Recommendations for Future Research}

Based on the findings, the researcher makes the following recommendations:

\section{Ugu District Mobile Injection Team}

a) That the drafted guidelines in this study will be useful if implemented and reviewed.

\section{Research in Other Health Districts}

Similar research is highly recommended in other health districts to understand the experiences of their injection teams, as this current research may not be generalised to the whole of KZN.

\section{Limitations of the Study}

These experiences are only those of the MDR-TB mobile injection teams from Ugu District and cannot be generalised to other districts. The selection of participants was limited, and team members worked together and had similar experiences. Interviews were conducted in English, and although participants understand the language and it is the language used at work, the researcher suspects that using isiZulu may have yielded more information on their experiences.

\section{Acknowledgement}

All authorities that granted permission for conducting this study are thanked, The National Research Foundation (NRF), for its financial assistance towards this research is hereby acknowledged (opinions expressed and conclusions arrived at are those of the authors and should not necessarily be attributed to the NRF) and the participants who shared their experiences.

\section{References}

1. Ormerod LP (2005) Multidrug-resistant tuberculosis (MDR-TB): Epidemiology, prevention and treatment. Br Med Bull 73-74: 17-24.

2. Department of Health (Republic of South Africa) (2014) National tuberculosis management guidelines.

3. Wallengren K, Scano F, Nunn P, Margot B, Sandile SS Buthelezi, et al. (2011) Drug-Resistant Tuberculosis, KwaZulu-Natal, South Africa, 20012007. Emerging Infectious Diseases 17(10): 1913-1916.
4. Loveday M, Rhil M, Wallegren PM, Voce K, Margot B, et al. (2015) Community-based care vs. centralised hospitalisation for MDR-TB patients KwaZulu-Natal, South Africa. Int Tuberc Lung Dis 19(2): 163171.

5. Meressa D, Hurtado RM, Andrews JR, Diro E, Abato K, et al. (2015) Achieving high treatment success for Multidrug-resistant TB in Africa: Initiation and scale-up of MDR TB care in Ethiopia-an observational cohort study. Thorax 70(12):1181-1188.

6. Department of Health (Republic of South Africa) (2011) Multi-drug resistant tuberculosis: A policy framework on decentralised and deinstitutionalised management for South Africa.

7. South African Nursing Council (2005) Nursing Act (No-33).

8. South African Nursing Council (1991) Regulations relating to the scope of practice of persons who are registered or enrolled under the Nursing Act, 1978.

9. http://wordreference.com/definition/esperience:English

10. Oxford Mini School Thesaurus (2007) New York: Oxford University Press.

11. Marshall C, Rossman GB (2006) Designing Qualitative Research $\left(4^{\text {th }}\right.$ edn.); Thousand Oaks, CA: Sage.

12. Leddy S, Pepper JM (1993) Conceptual Bases of Professional Nursing ( $3^{\text {rd }}$ edn.); Philadelphia: JP Lippincott company.

13. Streubert Speziale HJ and Carpenter DR (2003) Qualitative research in nursing: Advancing the humanistic imperative $\left(3^{\text {rd }} \mathrm{edn}\right)$. Lippincott Williams and Wilkins, New York, USA.

14. De Castro Alberto (2003) Introduction to Giorgi's Existential Phenomenological Research Method.

15. Brust JCM, Shah NS, Scott M, Chaiyachati K, Lygizos M, et al. (2012) Integrated, home-based treatment for MDR-TB and HIV in rural South Africa: An alternate model. Int J Tuberc Lung Dis 16(8): 998-1004.

16.WWW.BROWN.UK.COM/TEACHING/QUALITATIVEPOSTGRAD/GIORGI. PDF

17. Burns N, Grove SK (2007) The practice of nursing research: Conduct, critique and utilization ( $7^{\text {th }}$ edn.); Philadelphia: Saunders.

18. http://www.sahivsoc.org/upload/documents/NTCP_Adult_TB\%20 Guidelines\%2027.5.2014.pdf

19. De Vos AS, Strydom H, Fouché CB, Delport CSL (2005) Research at grass roots ( $3^{\text {rd }}$ edn); Pretoria: Van Schaik.

20. George JB (2011) Nursing theories: The base for professional nursing practice $\left(6^{\text {th }}\right.$ edn); Pearson Education, New Jersey, USA.

21. Polit DF and Beck CT (2017) Nursing research: Generating and Assessing Evidence for Nursing Practice $\left(10^{\text {th }}\right.$ edn) Philadelphia: Wolters Kluwer.

22. Streubert Speziale HJ and Carpenter DR (2007) Qualitative research in nursing: Advancing the humanistic imperative $\left(4^{\text {th }} \mathrm{edn}\right)$; New York: Lippincott Williams and Wilkins.

23.h t t p : / / a p p s. w h o. i n t / i r i s / bitstream/10665/43965/1/9789241547581_eng.pdf

24. World Health Organization (WHO) (2011) Guidelines for the programmatic management of drug-resistant tuberculosis. saGeneva: World Health Organization.

25.h t t p : / / a p p s. wh o. in t/ i r i s / b i t s t r e am/10665/44597/1/9789241501583_eng.pdf 
ISSN: 2574-1241

DOI: 10.26717/BJSTR.2018.09.001736

Sitha Devi Arjun. Biomed J Sci \& Tech Res

(c) (P) This work is licensed under Creative

Submission Link: https://biomedres.us/submit-manuscript.php

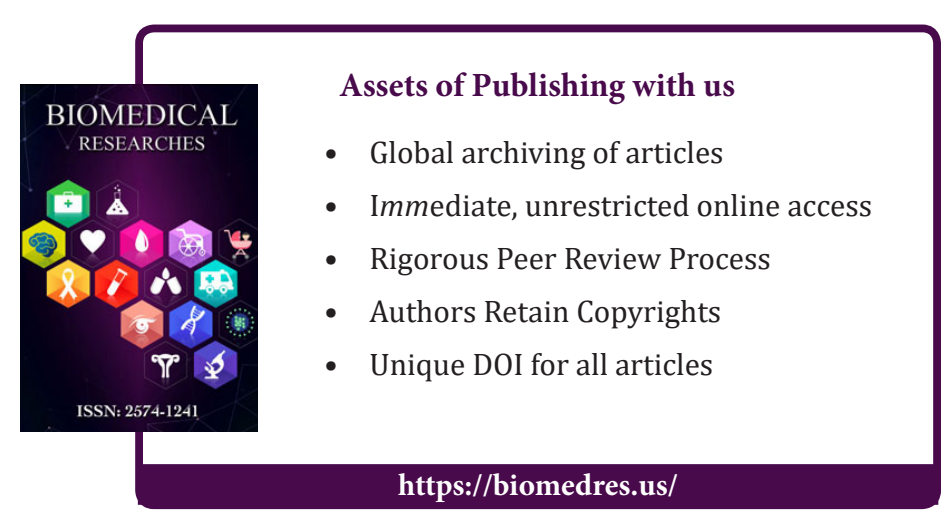

